\title{
Requirements for Leukocyte Adhesion Molecules in Nephrotoxic Nephritis
}

\author{
Michael S. Mulligan, * Kent J. Johnson, * Robert F. Todd III," Thomas B. Issekutz," Masayuki Miyasaka," Takuya Tamatani," \\ C. Wayne Smith," Donald C. Anderson," " " and Peter A. Ward" \\ Departments of * Pathology and ${ }^{\ddagger}$ Internal Medicine, The University of Michigan Medical School, Ann Arbor, Michigan 48109; \\ ${ }^{\S}$ Departments of Pediatrics and Microbiology, Dalhousie University, Halifax, Canada B3I 3G9; "Department of Immunology, Tokyo \\ Metropolitan Institute of Medical Science, Tokyo 113, Japan; and Departments of \\ ** Pediatrics and 'Cell Biology, Baylor College of Medicine, Houston, Texas 77030
}

\begin{abstract}
Requirements for leukocyte adhesion molecules as well as cytokines have been determined in the rat model of acute nephrotoxic nephritis. Proteinuria (at $24 \mathrm{~h}$ ) and neutrophil accumulation in renal glomeruli (at $6 \mathrm{~h}$ ) have been used as the endpoints. For full accumulation in glomeruli of neutrophils as well as full development of proteinuria, requirements have been demonstrated for TNF, (but not IL-1), CD11b (but not CD11a), very late arising-4 (CD49d/CD29), and intercellular adhesion molecule-1 but not endothelial leukocyte adhesion molecule-1 (E-selectin). By immunohistochemical approaches, infusion of antibody to glomerular basement membrane induced glomerular upregulation of intercellular adhesion molecule-1, endothelial leukocyte adhesion molecule-1, and vascular adhesion mole-

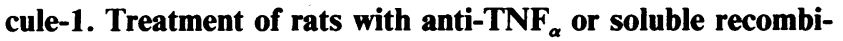
nant human TNF receptor-1 blocked this expression. Renal arterial infusion of $\mathrm{TNF}_{\alpha}$ induced glomerular expression of all three endothelial adhesion molecules, but infusion of IL-1 $\beta$ did not. These data suggest that, in neutrophil and complement-dependent anti-glomerular basement membrane-induced acute nephritis in rats, there are selective requirements for cytokines, $\beta 1$ and $\beta 2$ integrins, and endothelial adhesion molecules. These requirements contrast with those found in other vascular beds in which complement and neutrophil-induced vascular injury has been induced by deposition of immune complexes. (J. Clin. Invest. 1993.91:577-587.) Key words: nephritis • adhesion molecules $\bullet$ neutrophils $\bullet$ integrins $\bullet$ selectins
\end{abstract}

\section{Introduction}

Adhesion-promoting molecules appear to play important roles in development of the inflammatory response and in the recruitment of leukocytes into tissues. Adhesion-promoting molecules associated with leukocytes include the $\beta 1$ and the $\beta 2$ integrins, the latter consisting of the CD11/CD18 complex, and the other molecules such as L-selectin, a lectin-binding molecule that also presents the carbohydrate sialyl $\mathrm{Le}^{\mathrm{x}}$ to the other selectins (P- and E-selectin) (1). While the $\beta 2$ integrins can be upregulated during activation of leukocytes, L-selectin

Address correspondence to Peter A. Ward, M.D., The University of Michigan Medical School, Department of Pathology, 1301 Catherine Street, Box 0602, Ann Arbor, MI 48109.

Received for publication 7 April 1992 and in revised form 4 September 1992.

J. Clin. Invest.

(C) The American Society for Clinical Investigation, Inc.

$0021-9738 / 93 / 02 / 0577 / 11 \$ 2.00$

Volume 91, February 1993, 577-587 is shed during cell activation (2). In the case of endothelial cells, adhesion-promoting molecules are, in the main, not constitutively expressed, but their expression can be rapidly (in the case of P-selectin) or slowly (in the case of endothelial leukocyte adhesion molecule-1 [ELAM-1], ${ }^{1}$ intercellular adhesion molecule-1 [ICAM-1], or vascular adhesion molecule-1 [VCAM-1]) upregulated. There is considerable evidence that leukocyte and endothelial adhesion-promoting molecules play important roles in a variety of inflammatory reactions (3-7).

The current studies were designed to assess the roles of adhesion molecules and cytokines in the development of acute nephritis in rats after deposition of intraglomerular immune complexes after vascular infusion of heterologous (sheep) IgG antibody to glomerular basement membrane (anti-GBM). In this model of nephritis the acute phase of injury develops within $24 \mathrm{~h}$ and is characterized by linear glomerular deposition of the antibody along the GBM, complement fixation, neutrophil accumulation, and oxygen radical-dependent injury of the glomerular wall, resulting in acute proteinuria and damage/destruction of glomerular endothelial and epithelial cells (8). Since the cytokines $\mathrm{TNF}_{\alpha}$ and IL-1 are known to cause endothelial cell expression of adhesion molecules (9-11) and $\mathrm{TNF}_{\alpha}$ is crucial for the E-selectin-dependent influx of neutrophils into lungs after deposition of IgG immune complexes (3), the possible roles of $\mathrm{TNF}_{\alpha}$ and IL-1 in the development of IgG anti-GBM-induced glomerular injury were also assessed. The pattern of cytokine and adhesion molecule engagement in anti-GBM-induced nephritis in rats has some similarities and several distinctive differences when compared with the pattern of mediator engagement in rat lung after deposition of $\mathrm{IgG}$ immune complexes.

\section{Methods}

Reagents. Unless otherwise noted, all reagents were purchased from Sigma Chemical Co. (St. Louis, MO). As used in the protocols described below, none of the antibody preparations caused neutropenia after intravenous infusion. The control antibody preparations for the adhesion molecule studies were intact IgG 1 MOPC-21 or $F\left(a^{\prime}\right)_{2}$ of $\mathrm{IgG}_{1}$ from MOPC-21. For the former, $200 \mu \mathrm{g}$ was injected intravenously immediately after the infusion of anti-GBM antibody. In the case of $\mathrm{F}\left(\mathrm{ab}^{\prime}\right)_{2}, 67 \mu \mathrm{g}$ was injected 2,4 , and $6 \mathrm{~h}$ after infusion of

1. Abbreviations used in this paper: ELAM-1, endothelial leukocyte adhesion molecule-1 (E selectin); GBM, glomerular basement membrane; ICAM-1, intercellular adhesion molecule-1; IL-1 ra, IL-1 receptor antagonist; LFA-1, CD11a/CD18 heterodimer; Mac-1, CD11b/ CD18 heterodimer; RPAEC, rat pulmonary artery endothelial cells; sTNFr-1, human recombinant soluble tumor necrosis factor receptor1; VCAM-1, vascular adhesion molecule-1; VLA-4, very late arising4(CD49d/CD18). 
anti-GBM. This schedule was selected because of the short half-life of $\mathrm{F}\left(\mathrm{ab}^{\prime}\right)_{2}$ in the plasma and because of the time course (as assessed by immunohistochemical analysis) of adhesion molecule expression in glomeruli after infusion of anti-GBM. Anti-ELAM-1 (CL-3) was generated by immunization of mice with IL-1-stimulated human umbilical vein endothelial cells and the appropriate hybridomas obtained. This antibody, which reacts with tumor necrosis factor alpha $\left(\mathrm{TNF}_{\alpha}\right.$ )-stimulated rat pulmonary artery endothelial cells (RPAEC), has been described in a recent report (3). The $F\left(a b^{\prime}\right)_{2}$ preparation rather than intact $\mathrm{IgG}_{1}$ was used, since the intact antibody neither prevents adherence of phorbol ester-stimulated rat blood neutrophils to $\mathrm{TNF}_{\alpha}$-treated RPAEC nor does it protect against IgG immune complex-induced acute lung injury, in contrast to the $\mathrm{F}\left(\mathrm{ab}^{\prime}\right)_{2}$ preparation of the same antibody (3). For use, $45 \mu \mathrm{g} \mathrm{F}\left(\mathrm{ab}^{\prime}\right)_{2}$ CL-3 was injected intravenously 2,4 , and $6 \mathrm{~h}$ after infusion of anti-GBM. In an additional experiment the dose of $F\left(a b^{\prime}\right)_{2}$ anti-ELAM- 1 was tripled, with intravenous injection of $133 \mu \mathrm{g}$ at times 2,4 , and $6 \mathrm{~h}$. IgG antibody to human VCAM-1 was prepared in goats and found to be cross-reactive with $\mathrm{TNF}_{\alpha}$-stimulated RPAEC. Due to limited available quantities, this antibody was available only for immunohistochemical analysis. Antibody to rat ICAM-1 was used as the $F\left(a b^{\prime}\right)_{2}$ preparation of IgG $_{1}$ (1A29) and was obtained from hybridomas after immunization of mice with endothelial cells obtained from high endothelial venules of rat lymph nodes. This antibody preparation is described in detail elsewhere (12). When used, doses of $200 \mu \mathrm{g} 1 \mathrm{~A} 29 \mathrm{~F}\left(\mathrm{ab}^{\prime}\right)_{2}$ were injected intraperitoneally and intravenously, each, $1 \mathrm{~h}$ after infusion of antiGBM. This protocol was selected to address the problem of constitutive vascular expression of ICAM-1. A second protocol for treatment with anti-ICAM-1 was also used. This consisted of three intravenous injections of $133 \mu \mathrm{g}$ of antibody 2, 4, and $6 \mathrm{~h}$ after anti-GBM. This amounted to a total intravenous dose of $399 \mu \mathrm{g}$ as compared with the $200 \mu \mathrm{g}$ intravenous dose in the first protocol. Anti-very late arising-4 (CD49d/CD29) (VLA-4) (TA-2) was obtained by immunization of mice with lymphocytes obtained from peritoneal exudates of rats and the appropriate hybridomas obtained. This antibody was of the $\mathrm{IgG}_{1}$ class, was reactive with the $\alpha 4$ chain (CD49d) of $\beta 1$ integrin, and blocked binding of rat lymphocytes to cytokine-activated vascular endothelial cells (13). When used, $0.25 \mathrm{ml}(800 \mu \mathrm{g}) \mathrm{TA}-2 \mathrm{IgG}_{1}$ was infused intravenously at time 0 and $4 \mathrm{~h}$. Using this protocol, a single intravenous injection of this antibody strongly inhibits lymphocyte accumulation in delayed-type cutaneous hypersensitivity reactions in rats (14). Blood neutrophil counts (cells $/ 0.1 \mathrm{~mm}^{3}$ blood) at times 0,2 , 4,6 , and $24 \mathrm{~h}$ after infusion of TA-2 were: $145 \pm 2.5,132 \pm 4.1,135 \pm 2.7$, $139 \pm 3.3$ and $141 \pm 3.4$, respectively. WT- 1 anti-rat CD11a (LFA-1) was an $\mathrm{IgG}_{2 \mathrm{a}}$ murine monoclonal antibody that has been recently described in detail (15). Anti-CD11a was used as an intact antibody, since it did not induce a neutropenia (data not shown). When used, $200 \mu \mathrm{g}$ WT. 1 anti-CD1 1 a was injected intravenously immediately after intravenous infusion of anti-GBM. Anti-rat CD11b (1B6c) was an $\mathrm{IgG}_{1}$ murine monoclonal antibody obtained by immunization of mice with rat peritoneal neutrophils that had been obtained by intraperitoneal instillation of glycogen. This antibody is characterized in detail elsewhere (Mulligan, M. S., M. Miyasaka, T. Tamatani, R. F. Todd III, W. C. Smith, D. C. Anderson, and P. A. Ward, manuscript submitted for publication). Briefly, the antibody blocks adhesion of rat neutrophils to keyhole limpet hemocyanin-coated plastic surfaces, binds (as assessed by flow cytometry) to rat neutrophils but not to rat lymphoid cells, inhibits aggregation of rat neutrophils in response to phytohemagglutinin, immunoabsorbs from rat neutrophils a heterodimeric protein with features of Mac-1 (CD11b/CD18), and demonstrates increased reactivity with rat neutrophils that have been activated with $N$-formyl-Met-Leu-Phe, as assessed by flow cytometry. (When used, $300 \mu \mathrm{g}$ intact $\mathrm{IgG}_{1}$ anti-CD11 b was infused intravenously. No neutropenia developed under these conditions [data not shown]). This antibody was generously made available by the Repligen Corp. (Cambridge, MA) by Dr. James Rusche. Anti-rat CD18 (CL-26), a murine $\mathrm{IgG}_{1}$, was obtained from murine hybridomas after immunization with rat splenic lymphocytes. CL-26 anti-CD18 exhibited binding to rat neutrophils, lymphocytes, and monocytes and, by immunoprecipitation using ${ }^{125}$ I-surface-labeled rat neutrophils or spleen cells, reacted with a $95-\mathrm{kD}$ protein, consistent with the $\beta$ chain of $C D 18$. Since intravenous infusion of intact $\mathrm{IgG}_{1} \mathrm{CL}-26$ produced neutropenia ( $200 \mu \mathrm{g}$ causing neutrophil counts to fall by $43 \%$ by $2 \mathrm{~h}$ and $66 \%$ by $4 \mathrm{~h}$ ), $F\left(a b^{\prime}\right)_{2}$ fragments were prepared and were found not to induce neutropenia. When used, $33 \mu \mathrm{g} \mathrm{F}\left(\mathrm{ab}^{\prime}\right)_{2} \mathrm{CL}-26$ were injected at times 2 , 4, and $6 \mathrm{~h}$ after infusion of anti-GBM. This protocol has been found to provide high degrees of protection against neutrophil-mediated lung injury (16). Anti-TNF ${ }_{\alpha}$ was a polyclonal goat IgG antibody raised to recombinant murine $\mathrm{TNF}_{\alpha}$ and found to cross-react with rat $\operatorname{TNF}_{\alpha}(17,18)$. When used, $1.0 \mathrm{ml}$ immune goat serum was injected intravenously immediately after infusion of anti-GBM. This treatment blocks appearance of $\mathrm{TNF}_{\alpha}$ in rat bronchoalveolar fluids after intrapulmonary deposition of IgG immune complexes (17). Anti-IL-1 was a polyclonal goat IgG antibody to murine recombinant IL- $\alpha$ and was found to be crossreactive with rat IL-1 (19). When used, $1.0 \mathrm{ml}$ goat serum was intravenously infused immediately after the anti-GBM. For all studies, blood neutrophil counts were obtained at time $0,2,4,6$, and $24 \mathrm{~h}$ after injection of blocking antibodies. The dosing schedules described above did not induce neutropenia (data not shown). Human recombinant $\mathrm{TNF}_{\alpha}$ and IL- $1 \beta$ were obtained from Cetus Corp (Emeryville, CA ) and were infused as a bolus into the renal artery, as $100 \mathrm{U}$ in a vol of $0.3 \mathrm{ml}$. Details of the procedures are provided in the text. Human recombinant IL-1 receptor antagonist (IL-1 ra) and human recombinant soluble TNF receptor-1 (sTNFr-1) were provided by Drs. Robert Thompson and Tadchiko Kohno (Synergen Co., Denver, CO) (20-23). $2 \mathrm{mg}$ IL-1 ra/ $\mathrm{kg}$ body wt were injected subcutaneously at times 0,6 , and 12 $\mathrm{h}$, in accord with an established protocol that provides profound IL-1 receptor blockade in rats $(22,23)$. When sTNFr- 1 was used, $2 \mathrm{mg}$ sTNFr- $1 / \mathrm{kg}$ body wt was injected subcutaneously at times 0,8 , and 16 $h$ after infusion of anti-GBM.

Anti-GBM nephritis model. Details of the preparation of this antibody are contained in several previous publications $(8,24)$. Rat glomeruli were isolated with sieving techniques and subsequently sonicated, washed, and subjected to centrifugation. The basement membrane preparations were then emulsified in Freund's complete adjuvant and intradermally injected into sheep. After three boosting immunizations, ammonium sulfate precipitation was used to obtain the IgG-enriched fraction, which was processed by anionic exchange chromatography and the IgG fraction absorbed with rat platelets, lymphocytes, and erythrocytes before use. Male Long-Evans specific pathogen-free rats (300-350 g; Charles River Breeding Laboratories, Inc., Portage, MI) were used in all studies. Intraperitoneal ketamine (25-50 $\mathrm{mg} / \mathrm{kg}$ body $\mathrm{wt}$ ) and sodium pentobarbital ( $50 \mathrm{mg} / \mathrm{kg}$ body $\mathrm{wt}$ ) were administered for sedation and anesthesia. $10 \mathrm{mg}$ anti-GBM $\operatorname{IgG}(0.25$ $\mathrm{ml}$ diluted in PBS to $0.5 \mathrm{ml}$ ) were intravenously injected and the animals housed in metabolic cages for up to $24 \mathrm{~h}$. Other negative control animals received an equivalent amount $(10 \mathrm{mg}$ ) of sheep IgG obtained from normal sheep serum. This preparation contained by limulus assay $4 \mathrm{pg} / \mathrm{ml}$. The injection volume was $0.25 \mathrm{ml}$, such that $1 \mathrm{pg}$ endotoxin was diluted into the blood volume, resulting in an entotoxin concentration of $\sim 67 \mathrm{fg} / \mathrm{ml}$. The anti-GBM preparation contained a level of endotoxin (as measured by the limulus clotting assay) of $2.6 \mathrm{pg} / \mathrm{ml}$. Accordingly, $0.65 \mathrm{pg}(0.25 \mathrm{ml})$ was injected intravenously upon administration of anti-GBM with an estimated final blood concentration of $43 \mathrm{fg} / \mathrm{ml}$. Total urinary protein was measured by the Lowry technique after initial precipitation of protein with trichloroacetic acid. Urinary protein levels were compared to those from animals that had received intravenous injections of saline instead of anti-GBM. Reference positive control animals were infused with anti-GBM and then received intravenous saline $(500 \mu \mathrm{l})$ or irrelevant antibody (MOPC-21, intact $\operatorname{IgG}_{1}$, or $F\left(a b^{\prime}\right)_{2}$ ) at the times indicated. Except as noted, animals were killed at $6 \mathrm{~h}$ (for histology) or at $24 \mathrm{~h}$ (for determination of proteinuria). Six separate experiments were carried out. For purposes of clarity and brevity, all results have been grouped into a single table.

Morphology. Kidneys from animals killed $6 \mathrm{~h}$ after anti-GBM infusion were fixed in glutaraldehyde and processed for light or transmis- 
sion electron microscopy. Plastic-embedded sections ( $1 \mu \mathrm{m}$ thick) of kidneys from animals from each relevant group (negative controls, and untreated positive controls, or positive controls treated with the indicated reagents) were analyzed for the number of neutrophils per glomerulus according to procedures described elsewhere (8). These sections were stained with toluidine blue. Neutrophil content in glomerular capillaries or along glomerular walls was quantitated by examination of at least 50 glomeruli. Neutrophil counts were expressed as neutrophils/glomeruli (mean \pm SEM).

Immunohistochemical analysis. Additional sections of kidneys from animals sacrificed at the times indicated were embedded in O.C.T. compound (Miles Inc., Elkhart, IN) and snap-frozen in liquid nitrogen. After mounting on poly-L-lysine-coated slides, sections were fixed in acetone and incubated with MOPC-21 $(1 \mathrm{ng} / \mathrm{ml})$, antiELAM-1 (CL-3, $1.0 \mathrm{ng} / \mathrm{ml})$, anti-ICAM-1 (1:200 dilution), anti-

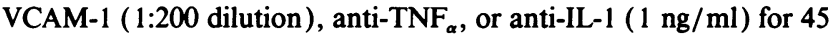
$\mathrm{min}$. The sections were then washed with PBS. Staining for presence of indicator antibody was achieved using the Vectastain biotin-avidin peroxidase (Vector Laboratories, Inc., Burlingame, CA) system for mouse IgG or goat IgG (in the case of VCAM-1). After hematoxylin counterstaining, sections were coated with aqua-mount (Lerner Laboratories, Pittsburgh, PA) and examined by light microscopy for the presence of reaction products of peroxidase.

Statistical analysis. The data were analyzed using analysis of variance and additional paired Student's $t$ tests to determine which individual group differences were statistically significant. All values were expressed as mean \pm SEM unless otherwise indicated. Statistical signifcance was defined as $P<0.05$. For purposes of statistical comparison and calculation of percent reduction of proteinuria, the mean proteinuria values of negative controls were subtracted from all values of the positive control groups and the various positive control treatment groups.

\section{Results}

Interventional effects on proteinuria. From six experiments, the collective data from various interventions and their effects on proteinuria are presented in Table I. Details of the interventions are provided above. The protocols for injection were determined by the ability of these reagents to provide protective effects in other inflammatory models in rats. Also, the choice of intact $\mathrm{IgG}_{1}$ antibody versus the use of $\mathrm{F}\left(\mathrm{ab}^{\prime}\right)_{2}$ was dictated by earlier experience in which some intact antibody preparations caused neutropenia. Negative controls were infused with PBS (Table I, group A) or with $10 \mathrm{mg} \mathrm{IgG}$ from normal sheep serum (Table I, group B). Positive controls (injected with PBS or with $200 \mu \mathrm{g} \mathrm{MOPC}-21 \mathrm{IgG}_{1}$ at time 0 , or with $67 \mu \mathrm{g} \mathrm{F}\left(\mathrm{ab}^{\prime}\right)_{2}$ MOPC21 doses at 2, 4, and $6 \mathrm{~h}$ after infusion of anti-GBM) demonstrated significant increases in proteinuria from 75 to $79 \mathrm{mg} /$ $24 \mathrm{~h}$ as compared with the negative control groups (10.3-11.1 $\mathrm{mg} / 24 \mathrm{~h}$ ) (Table I). There were no statistical differences within the three positive control groups. In striking contrast, treatment with anti-TNF $\mathrm{TN}_{\alpha}$ or with sTNFr-1 reduced proteinuria by $75.7 \%(P<0.001)$ and $76.0 \%(P<0.001)$, respectively, but treatment with either anti-IL-1 or IL-1 ra failed to reduce proteinuria significantly below the values of the positive reference controls ( $P$, NS). For whatever reason, treatment with anti-IL-1 actually slightly increased proteinuria (by $23.1 \%$ ), but this was not statistically significant when compared to the positive controls. Treatment with anti-CD11a did not reduce the proteinuria value (it actually rose by $4 \%$ ), but treatment with anti-CD1lb caused a marked reduction $(46.0 \%, P$

Table I. Effects of Interventions on Proteinuria

\begin{tabular}{|c|c|c|c|c|c|}
\hline Group* & Intervention $^{\ddagger}$ & $n$ & Proteinuria & Protection & $P$ valuell \\
\hline & & & $m g / 24 h^{8}$ & $\%$ & \\
\hline Negative control (A) & PBS & 27 & $10.3 \pm 0.37$ & & \\
\hline Negative control (B) & PBS & 4 & $11.1 \pm 0.11$ & & \\
\hline Positive control & PBS & 28 & $75.5 \pm 2.3$ & & \\
\hline Positive control & Irrelevant IgG $_{1}$ & 8 & $79.0 \pm 1.8$ & -4.46 & NS \\
\hline Positive control & Irrelevant $F\left(a^{\prime}\right)_{2}$ & 5 & $77.4 \pm 6.4$ & -2.91 & NS \\
\hline Positive control & Anti-TNF $\alpha$ & 8 & $26.1 \pm 0.88$ & 75.7 & $<0.001$ \\
\hline Positive control & sTNFr-1 & 4 & $26.0 \pm 2.8$ & 76.0 & $<0.001$ \\
\hline Positive control & Anti-IL-1 & 8 & $90.6 \pm 2.9$ & -23.1 & NS \\
\hline Positive control & IL-1 ra & 8 & $65.3 \pm 5.7$ & 15.6 & NS \\
\hline Positive control & Anti-CD11a & 4 & $110.0 \pm 6.8$ & $-4.0^{\prime}$ & NS \\
\hline Positive control & Anti-CD11b & 8 & $49.0 \pm 1.9$ & 46.0 & $<0.001$ \\
\hline Positive control & Anti-CD18 & 8 & $34.3 \pm 2.5$ & 63.1 & $<0.001$ \\
\hline Positive control & Anti-VLA-4 & 7 & $53.3 \pm 1.7$ & 34.0 & $<0.001$ \\
\hline Positive control & Anti-ICAM-1 & 4 & $60.0 \pm 1.8$ & 23.7 & $<0.001$ \\
\hline Positive control & Anti-ICAM-1 (2x) & 4 & $47.0 \pm 2.0$ & $55.0^{* *}$ & $<0.001$ \\
\hline Positive control & Anti-ELAM-1 & 8 & $84.3 \pm 2.9$ & -13.4 & NS \\
\hline Positive control & Anti-ELAM-1 (3x) & 4 & $92.0 \pm 2.3$ & $1.0^{* *}$ & NS \\
\hline
\end{tabular}

\footnotetext{
* Negative control (A) received only PBS intravenously. Negative control B group received $10 \mathrm{mg}$ normal sheep IgG; proteinuria values over the next $24 \mathrm{~h}$ were measured. All positive controls received $10 \mathrm{mg} \mathrm{IgG}$ anti-GBM. ${ }^{\ddagger}$ See text for details of interventions. ${ }^{8}$ Percent reduction of proteinuria as compared with the positive controls with no interventions. Negative control values were subtracted from all positive control values in order to compute percent reduction. "All comparisons for proteinuria values were made to the positive control group receiving PBS. 'In this particular experiment, the proteinuria values $(\mathrm{mg} / 24 \mathrm{~h})$ in the negative and positive control groups were $9.5 \pm 0.25$ and $106 \pm 3.4$, respectively. ${ }^{* *}$ For these experiments proteinuria values for negative and positive controls (receiving $\mathrm{F}\left(\mathrm{ab}^{\prime}\right)_{2} \mathrm{MOPC}-21$ as $133 \mu \mathrm{g}$ each intravenously at 2,4 ; and $6 \mathrm{~h}$ ) were $9.5 \pm 0.25$ and $93 \pm 1.3 \mathrm{mg} / 24 \mathrm{~h}$, respectively. The intravenous doses of anti-ICAM-1 and anti-ELAM-1 (both as F(ab') ${ }_{2}$ fragments) were $133 \mu \mathrm{g}$, each, injected intravenously at 2,4 , and $6 \mathrm{~h}$. Thus, the total intravenous anti-ICAM-1 dose was doubled while the antiELAM-1 dose was tripled as compared with companion experiments at lower doses of antibodies.
} 

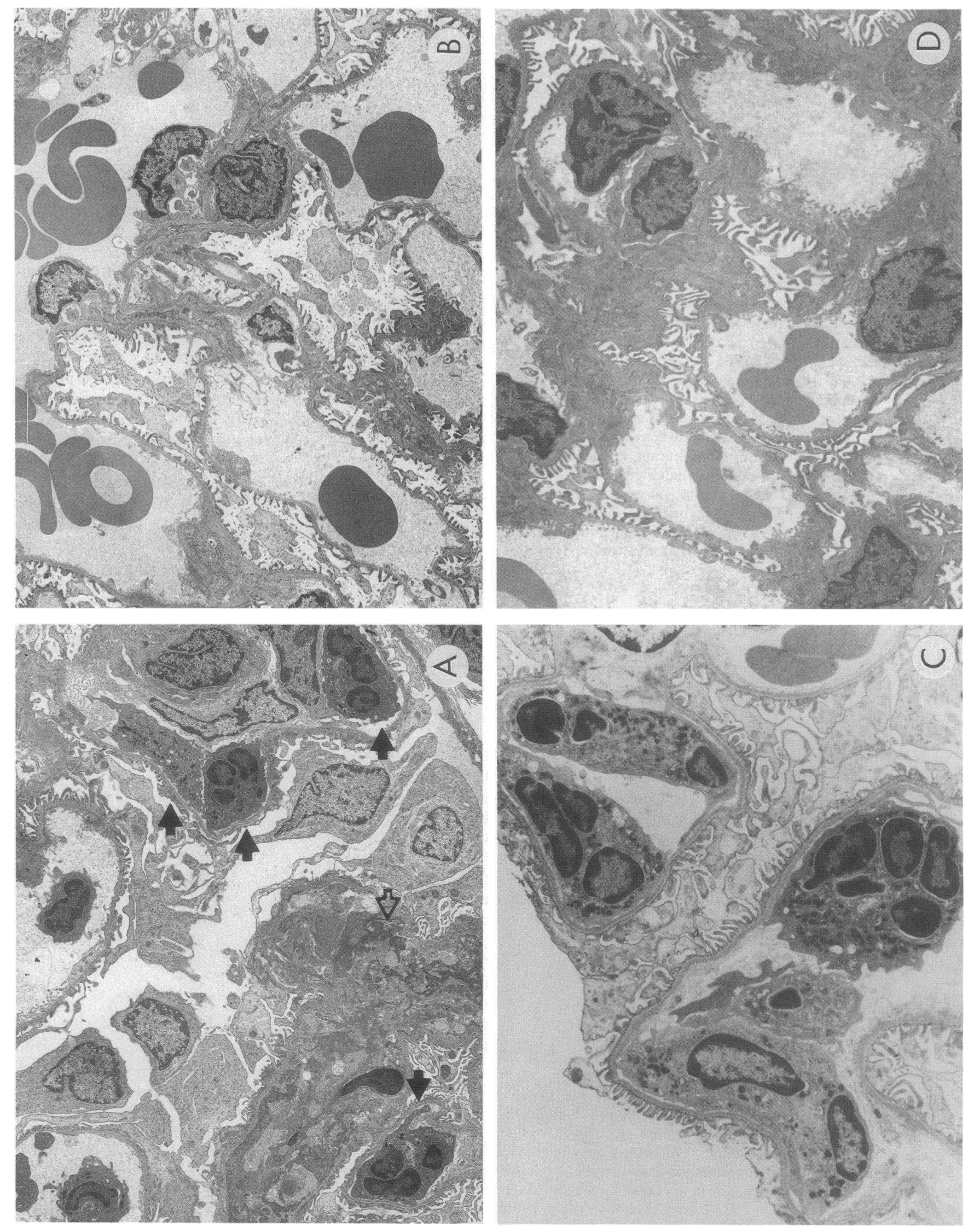
Table II. Effects of Interventions on Neutrophil Accumulation in Glomeruli

\begin{tabular}{|c|c|c|c|c|}
\hline Group* & Intervention & $\begin{array}{c}\text { Neutrophils } \\
\text { per glomerulus }\end{array}$ & $\begin{array}{l}\text { Percent } \\
\text { reduction in } \\
\text { neutrophils }\end{array}$ & $\begin{array}{c}\text { Significance } \\
(P \text { value })^{\prime \prime}\end{array}$ \\
\hline \multicolumn{5}{|l|}{ Negative control } \\
\hline (A) & PBS & $0.238 \pm 0.052$ & & \\
\hline \multicolumn{5}{|l|}{ Negative control } \\
\hline (B) & PBS & $0.233 \pm 0.048$ & & \\
\hline Positive control & PBS & $2.174 \pm 0.194$ & & \\
\hline Positive control & Anti-TNF $\alpha$ & $0.580 \pm 0.074$ & 82.3 & $<0.001$ \\
\hline Positive control & sTNFr-1 & $0.703 \pm 0.071$ & 76.0 & $<0.001$ \\
\hline Positive control & Anti-IL-1 & $2.09 \pm 0.115$ & 5.37 & NS \\
\hline Positive control & IL-1 ra & $2.33 \pm 0.121$ & 8.05 & NS \\
\hline Positive control & Anti-CDIla & $1.964 \pm 0.95$ & 10.8 & NS \\
\hline Positive control & Anti-CD1 lb & $0.886 \pm 0.095$ & 66.5 & $<0.001$ \\
\hline Positive control & Anti-CD18 & $0.634 \pm 0.093$ & 79.5 & $<0.001$ \\
\hline Positive control & Anti-VLA-4 & $0.95 \pm 0.008$ & 63.2 & $<0.001$ \\
\hline Positive control & Anti-ICAM-1 & $1.12 \pm 0.09$ & 54.4 & $<0.001$ \\
\hline Positive control & Anti-ELAM-1 & $2.36 \pm 0.098$ & -10.1 & NS \\
\hline
\end{tabular}

* Similar to those described in Table I. Negative controls A received PBS intravenously while negative controls $B$ received $10 \mathrm{mg}$ normal sheep IgG. All positive controls received $10 \mathrm{mg}$ IgG anti-GBM intravenously. ${ }^{\ddagger}$ As described in Table I. ${ }^{\S}$ Glomerular counts in at least 50 glomeruli per group were determined. See text for details. "As compared to the positive control group receiving PBS. Before calculations, the negative control value was subtracted from the positive control values.

$<0.001)$ in the degree of proteinuria. Treatment with $\mathrm{F}\left(\mathrm{ab}^{\prime}\right)_{2}$ anti-CD-18 dramatically reduced proteinuria, by $63.1 \%(P$ $<0.001)$, while treatment with either anti-VLA-4 or antiICAM-1 reduced proteinuria values by $34.0 \%(P<0.001)$ and $23.7 \%(P<0.001)$, respectively. When the protocol for treatment with $\mathrm{F}\left(\mathrm{ab}^{\prime}\right)_{2}$ anti-ICAM-1 was modified such that the injection schedule was intravenously at 2,4 , and $6 \mathrm{~h}$ ( similar to the anti-CD18 protocol ) and the dose of anti-ICAM-1 was doubled (to a total of $400 \mu \mathrm{g}$ ), the protection against proteinuria increased to $55.0 \%(P<0.001)$. In striking contrast to the blocking effects of $F\left(a b^{\prime}\right)_{2}$ anti-ELAM-1 in IgG immune complex-induced injury of lung (3), this intervention did not reduce the level of proteinuria induced by anti-GBM; in fact, there was a slightly increased (by $13.4 \%$ ) but statistically insignificant increase in proteinuria as a result of treatment with anti-ELAM-1 (Table I). Using the same treatment protocol but increasing by threefold the amount of anti-ELAM-1 (to $400 \mu \mathrm{g}$ ), there still failed to be any evidence of protection ( Table I). This strongly implies that ELAM-1 is not required for the development of injury in this model of glomerular injury.

Effects of interventions on glomerular accumulation of neutrophils. Animals were killed $6 \mathrm{~h}$ after injection of anti-GBM and the plastic-embedded tissue sections were examined mor- phologically by light microscopy to determine the effects of various interventions on the accumulation of neutrophils in glomeruli. The 6-h time point was selected, since this is known to be the time at which maximal accumulation of neutrophils occurs after infusion of anti-GBM (24). Results from the morphometric analyses of glomeruli are presented in Table II. After the intravenous infusion of anti-GBM in PBS, there was a marked increase in the number of glomerular neutrophils. In contrast to the negative controls receiving PBS or $10 \mathrm{mg}$ normal sheep IgG in which few neutrophils accumulated ( $<0.240$ /glomerulus), the positive controls had a nearly 10 fold increase in neutrophil accumulation $(2.174 \pm 0.194$ neutrophils/glomerulus) $(P<0.001)$. In animals treated with antiTNF $_{\alpha}$ or sTNFr-1, the accumulation of neutrophils fell by $82.3 \%(P<0.001)$ and by $76 \%(P<0.001)$, respectively, whereas neither treatment with anti-IL-1 nor with IL-1 ra significantly reduced glomerular accumulation of neutrophils (for each, $P, \mathrm{NS}$ ). Treatment with anti-CD11a did not significantly reduce the neutrophil accumulation, but treatment with antiCD1 1b or with anti-CD18 reduced neutrophil counts in glomeruli by $66.5 \%(P<0.001)$ and $79.5 \%(P<0.001)$, respectively. Treatment with anti-VLA-4 or with anti-ICAM-1 reduced neutrophil accumulation by $63.2 \%(P<0.001)$ and $54.4 \%(P<0.001)$, respectively. In contrast, treatment with anti-ELAM-1, which in IgG immune complex-induced lung injury is protective and significantly reduces lung accumulation of neutrophils ( 3 ), neither reduced the amount of proteinuria (Table I) nor did it interfere with glomerular accumulation of neutrophils (Table II). Thus, the effects of interventions on proteinuria correlate closely with the effects on glomerular accumulation of neutrophils. Agents that were protective against proteinuria also reduced the glomerular localization of neutrophils in the model of anti-GBM induced nephritis.

Analysis by transmission electron microscopy. On the basis of electron microscopic analysis, there was, as expected, a correlation between protective interventions and morphological changes in glomeruli. As shown in Fig. $1, A$ and $C, 6 \mathrm{~h}$ after infusion of anti-GBM antibody, there were numerous intraglomerular neutrophils (solid arrows), many of which were in direct contact with glomerular basement membrane, as well as mesangial deposits of fibrin (Fig. $1 \mathrm{~A}$, open arrow). Denudation of the endothelial monolayer was evident. In addition, epithelial cell foot processes were fused. In animals injected with anti-GBM and also treated with anti-TNF ${ }_{\alpha}$, the features were in striking contrast: few, if any, neutrophils were present within glomerular capillary loops, there was much less evidence of endothelial injury, no fusion of epithelial cell processes occurred, and mesangial deposits of fibrin were not observed (Fig. 1, $B$ and $D$ ).

Expression in renal glomeruli of ELAM-1, ICAM-1, and $V C A M-1$. These studies were designed to determine if, by immunohistochemical approaches, there was detectable upregulation of ELAM-1, ICAM-1, and VCAM-1 in rat glomeruli after infusion of anti-GBM antibody or after intraarterial infusion into the renal artery of $\mathrm{TNF}_{\alpha}$ or IL-1. In vivo upregulation of

Figure 1. Transmission electron micrographs of kidneys from rats infused with anti-GBM $(A, C)$ or anti-GBM and anti-TNF $\alpha(B, D)$. In the positive control $(A, C)$, there are many intraglomerular neutrophils ( solid arrows), areas of damaged or denuded endothelium, fused epithelial cell foot processes, and mesangial accumulations of fibrin (open arrow). In anti-GBM-infused rats that had been pretreated with anti-TNF ${ }_{\alpha}$, few if any neutrophils accumulated in glomerular capillaries, no fusion of epithelial foot processes occurred, and there was much diminished evidence of glomerular endothelial damage $(B, D) .(A, B, \times 2,900 ; C, \times 5,500$, and $D, \times 4,000)$. 


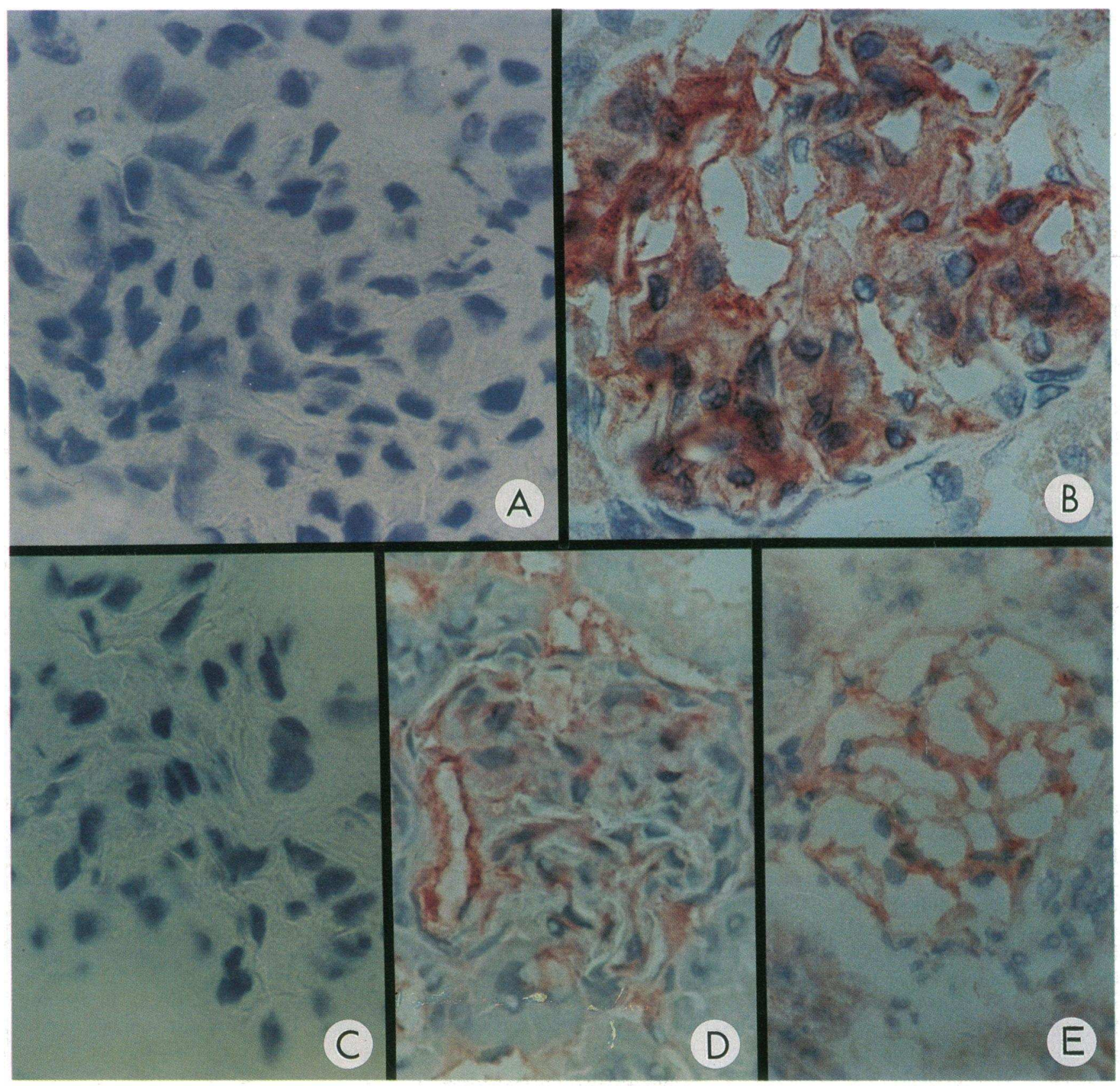

Figure 2. Immunohistochemical staining of renal glomeruli for VCAM-1, ELAM-1, and ICAM-1 $6 \mathrm{~h}$ after intravenous infusion of anti-GBM. In normal kidney, there was no detectable reactivity for VCAM-1 $(A)$, ELAM-1, or ICAM-1 (not shown). $6 \mathrm{~h}$ after injection of anti-GBM, there was staining of glomerular endothelial and mesangial areas for VCAM-1 $(B)$, with disappearance in VCAM-1 staining in anti-GBM injected animals pretreated with anti-TNF $\alpha(C)$ as well as loss of staining for ICAM-1 and ELAM-1 (data not shown). In anti-GBM-injected animals, glomerular staining for ICAM-1 $(D)$ and ELAM-1 $(E)$ was also evident. $(A-C, \times 400 ; D, \times 250 ; E, \times 200$.)

endothelial adhesion molecules after infusion of anti-GBM was also evaluated for the requirements for $\mathrm{TNF}_{\alpha}$ and IL-1. The time course for the in vivo expression of adhesion molecules was also established. Expression of ICAM-1, VCAM-1, and, to a lesser extent, ELAM-1 was detected as early as $2.0 \mathrm{~h}$ after infusion of anti-GBM, appeared to reach a peak at 4-6 h after infusion of the antibody, and diminished over the next 18 h (data not shown): Nephrotoxic nephritis was induced according to the protocols described above. Kidneys were har- vested 6 and $24 \mathrm{~h}$ after intravenous infusion of anti-GBM and frozen sections obtained. According to the procedures described above, tissues were then evaluated immunohistochemically for the presence of VCAM-1, ELAM-1, and ICAM-1. The findings from these experiments are described in Figs. 2 and 3. In animals infused with $10 \mathrm{mg}$ IgG from normal sheep serum, no staining for ICAM-1 or VCAM-1 was detected at $6 \mathrm{~h}$ (data not shown). Sections of kidneys from saline-infused animals that had not received anti-GBM failed to demonstrate detect- 

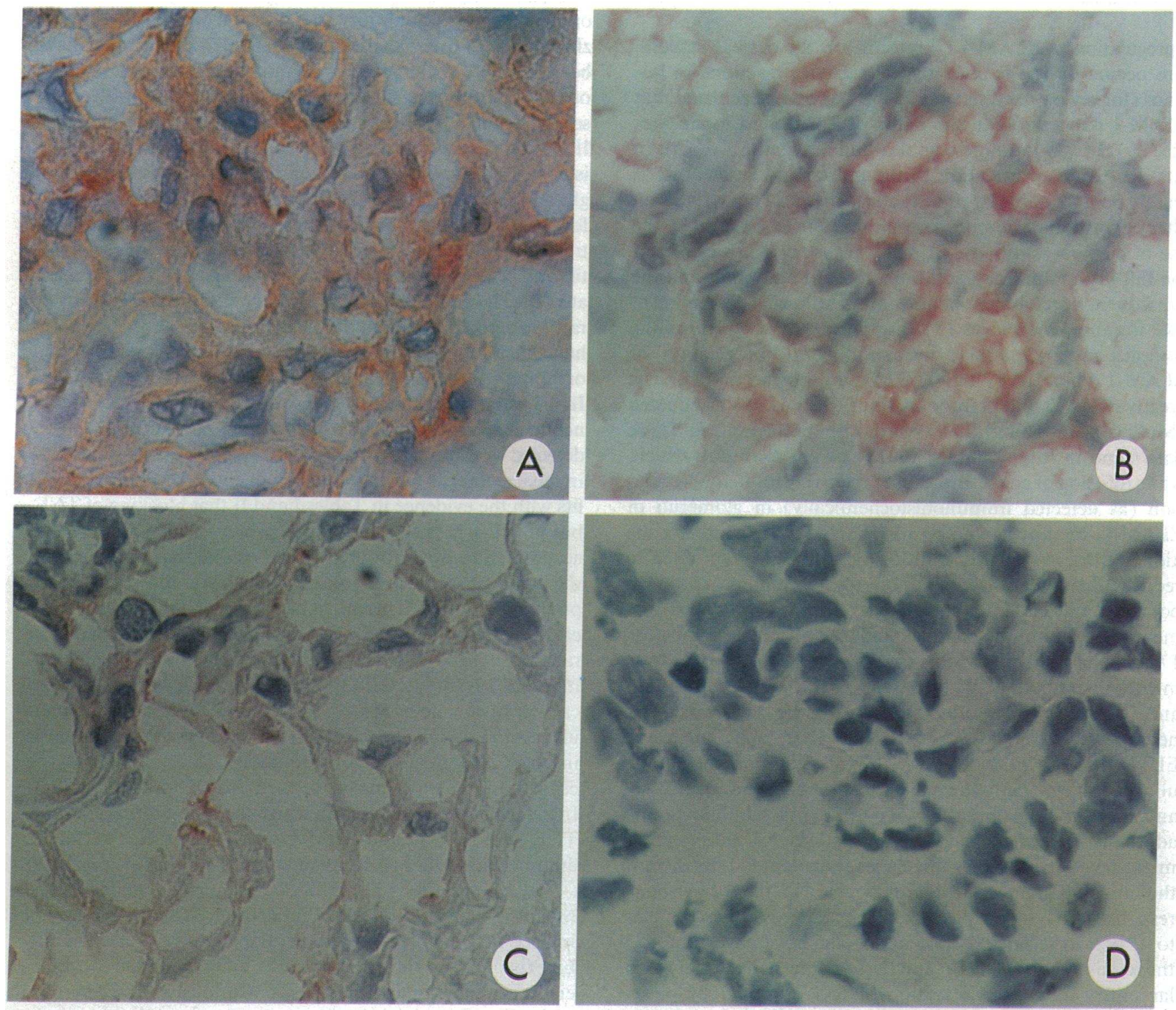

Figure 3. Immunohistochemical staining for vascular adhesion molecules $6 \mathrm{~h}$ after infusion into the renal artery of $100 \mathrm{U}$ of TNF $\alpha(A-C)$ or after infusion of $100 \mathrm{U}$ IL-1 $\beta(D)$. TNF $\alpha$ induced staining for VCAM-1 $(A)$, ELAM-1 $(B)$, and ICAM-1 $(C)$, but in IL-1 $\beta$-infused rats no staining for VCAM-1 was found $(D) .(A, C$, and $D, \times 400 ; B, \times 300$.)

able reactivity for VCAM-1 $6 \mathrm{~h}$ after infusion of PBS (Fig. $2 \mathrm{~A}$ ) or ELAM-1 in glomeruli (data not shown); barely detectable glomerular reactivity for ICAM-1 was occasionally found (data not shown ). Endothelial and mesangial reactivity for VCAM-1 was intensely expressed $6 \mathrm{~h}$ after infusion of anti-GBM antibody (Fig. $2 \mathrm{~B}$ ) and persisted at $24 \mathrm{~h}$ (data not shown). In animals pretreated with anti-TNF $\alpha$, the infusion of anti-GBM failed to induce detectable VCAM-1 staining at $6 \mathrm{~h}$ (Fig. $2 \mathrm{C}$ ). In otherwise untreated animals injected with anti-GBM, at $6 \mathrm{~h}$ staining for ICAM-1 (Fig. $2 D$ ) and ELAM-1 (Fig. $2 E$ ) was detected. Due to the constraints of frozen section technique, precise cellular or extracellular localization of the staining was difficult. When glomeruli obtained $6 \mathrm{~h}$ after infusion of antiGBM were reacted with IgG $_{1}$ MOPC-21, no glomerular staining was found (data not shown).

Rats received a unilateral infusion into a renal artery of 100 $\mathrm{U}$ of either TNF $\alpha$ or IL- $1 \beta$ and the kidneys obtained $6 \mathrm{~h}$ later.
Staining of these tissues revealed glomerular staining for VCAM-1 (Fig. $3 A$ ), ELAM-1 $(B)$, and ICAM-1 $(C)$. The staining appeared to be somewhat less intensive when compared with glomeruli after infusion of anti-GBM (Fig. 2). Kidneys infused intraarterially with IL- $1 \beta$ failed to show staining for VCAM-1 (Fig. 3 D), ICAM, or ELAM-1 (data not shown). These data indicate that anti-GBM causes upregulation in renal glomeruli of VCAM-1, ELAM-1, and ICAM-1, that this upregulation is $\mathrm{TNF}_{\alpha}$ dependent but IL-1 independent, and that the pattern of upregulation can be reproduced in vivo by intraarterial infusion into kidney of $\mathrm{TNF}_{\alpha}$, but not by infusion of IL- $1 \beta$.

When frozen sections of glomeruli from rats with antiGBM-induced nephritis were obtained at $6 \mathrm{~h}$ and stained for $\mathrm{TNF}_{\alpha}$ and IL-1, there was diffuse and strong staining for $\mathrm{TNF}_{\alpha}$ while little, if any, staining was detectable for IL-1 (data not shown). 


\section{Discussion}

Upregulation of ELAM-1 (E-selectin) in the dermal vasculature occurs during contact hypersensitivity reactions in humans (for review see reference 25 ). It has been speculated that ELAM-1 plays a role in the influx of $T$ cells and monocytes $(25,26)$. In IgG immune complex-induced acute alveolitis in rats, ELAM-1 upregulation in the pulmonary vasculature is readily demonstrable by immunohistochemical analysis $3-4 \mathrm{~h}$ after deposition of immune complexes ( 3 ). As revealed by the use of blocking antibody, ELAM-1 plays an obligate role for the full intrapulmonary accumulation of neutrophils and the subsequent development of lung injury following deposition of IgG immune complexes (3). Furthermore, in IgG immune complex-induced injury, intrapulmonary upregulation of ELAM-1 is blocked by anti-TNF $\alpha$, neutrophil accumulation is greatly reduced, and pulmonary injury is markedly attenuated (Mulligan, M. S., and P. A. Ward, unpublished data). These data stand in sharp contrast to the current studies in which, while infusion of anti-GBM caused relatively limited upregulation (as detected immunohistochemically) in glomeruli of ELAM-1, treatment with anti-ELAM-1 failed to protect the kidney from injury after infusion of anti-GBM and failed to reduce glomerular accumulation of neutrophils. Although both IL-1 and TNF $\mathrm{TN}_{\alpha}$ are known to be required for full development of IgG immune complex-induced alveolitis in rats (16, $17,19)$ and both are capable of inducing ELAM-1 expression in vitro on rat pulmonary artery endothelial cells (3), anti-IL-1 and IL-1 ra were not protective against the development of nephrotoxic nephritis (Table I) and IL-1 failed to induce ELAM-1, ICAM-1, and VCAM-1 expression in renal glomeruli when injected into the renal artery (Figs. 2 and 3). If TNF and IL-1 have an important role in vivo in the induction of adhesion molecule expression by endothelial cells, then it might be concluded that there are fundamental differences in the lung and glomerular microvasculatures, the former being responsive to both cytokines while the latter is only responsive to $\mathrm{TNF}_{\alpha}$. In recent experiments in which we have compared the requirements for $\mathrm{TNF}_{\alpha}$ and IL-1 for lung and dermal vascular injury following deposition of IgG immune complexes,

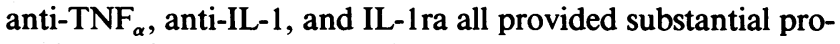
tection against lung vascular injury. In contrast, in dermal vascular injury induced by the same immune complexes, blocking of IL-1 was highly protective but blocking of $\mathrm{TNF}_{\alpha}$ was not protective. By immunohistochemical analysis, the dermal interstitium contained IL-1-positive cells but not cells containing $\mathrm{TNF}_{\alpha}(27)$. Thus, there appear to be distinct differences in vascular beds from different organs with respect to the pattern of cytokine engagement during development of the acute inflammatory response.

It should also be pointed out that there is evidence to suggest that rat endothelial cells can, under special circumstances, show selective responsiveness to cytokines. For instance, although the rat pulmonary vasculature responds with upregulation of ELAM-1 in response to both cytokines, and $\mathrm{TNF}_{\alpha}$ and IL-1 can both induce upregulation in vitro of ELAM- 1 in rat pulmonary artery endothelial cells $(3,10), \mathrm{TNF}_{\alpha}$, but not IL-1, causes in vitro conversion of xanthine dehydrogenase to xanthine oxidase in rat pulmonary artery endothelial cells (28). Thus, generalizations regarding responses of endothelial cells to cytokines are difficult.
The finding that IL-1 does not seem to be required for development of glomerular injury after infusion of anti-GBM is puzzling, since in other studies mRNA for IL-1 ra and IL-1 have been detected in glomeruli of nephritic animals, and infusion of IL-1 accentuates the nephritic state. Rabbits with acute serum sickness have been shown to exhibit slightly increased IL-1 production in isolated glomeruli, and exogenously administered $\mathrm{TNF}_{\alpha}$ and IL-1 enhanced the severity of this form of glomerulonephritis (29). Similarly, enhanced levels of mRNA for $\mathrm{TNF}_{\alpha}$ and IL- $1_{\beta}$, but not IL- $1_{\alpha}$, have been detected in extracts of the renal cortex in MLR-1 pr mice with lupus nephritis, and pretreatment of these mice with IL-1 or TNF $\alpha$ accelerated the development of renal injury (30). Sprague-Dawley rats with nephrotoxic-induced nephritis also have shown enhancement of injury following infusion of LPS, human $\mathrm{TNF}_{\alpha}$, or human IL-1 ${ }_{\beta}(31)$. Accordingly, enhanced $\mathrm{TNF}_{\alpha}$ and/or IL-1 formation appears to be occurring in renal glomeruli of nephritic animals, at least under certain conditions. Why we detected by immunoperoxidase technology TNF $\mathrm{TN}_{\alpha}$ but not IL-1 in renal glomeruli $6 \mathrm{~h}$ after infusion of anti-GBM is unclear but fits with the evidence in Tables I and II that blocking of TNF but not IL-1 is protective against proteinuria and glomerular accumulation of neutrophils. It is possible that in our model the acute phase of nephrotoxic nephritis is too brief for the production of IL-1. This might be the reason for the renal cortical presence of mRNA for IL-1 in chronic nephritic models in rabbits (29) and mice (30). In experiments in which pretreatment (at $1 \mathrm{~h}$ ) of rats with LPS, IL-1, or $\mathrm{TNF}_{\alpha}$ has been shown capable of enhancing injury (the degree of proteinuria, glomerular accumulation of neutrophils and intravascular thrombosis in anti-GBM-treated rats), the dosage of cytokines may be critical. In our experiments we used $\sim 0.01 \mu \mathrm{g} \mathrm{TNF}_{\alpha}$ or IL-1. In the in vivo studies in rats in which the exacerbating effects of $\mathrm{TNF}_{\alpha}$ and IL-1 on anti-GBM-induced nephritis were found, 50 times more IL-1 $(0.5 \mu \mathrm{g})$ and 400-4,000 times more $\mathrm{TNF}_{\alpha}$ $(4-40 \mu \mathrm{g})$ were used (31). Thus, our failure to demonstrate the role of IL- 1 in the anti-GBM model as well as the inability of infused IL-1 to upregulate glomerular adhesion molecules may be explained by these quantitative differences and by differences in experimental protocols. Curiously, $\mathrm{PGE}_{1}$-induced protection against the chronic phase of nephritis has been associated with increased rather than decreased production of IL-1, suggesting that $\mathrm{PGE}_{1}$ may cause dissociation in the formation of IL-1 and other cytokines, such as $\operatorname{TNF}_{\alpha}(32)$. Such a finding might be due to increased production of IL-1 ra which would counter any biological effect of IL-1. Whether or not IL-1 production is occurring in the early phase of nephrotoxic nephritis, our studies do not support the conclusion that IL-1 is required for the events in this phase of nephritis. For whatever reason, it would seem that $\mathrm{TNF}_{\alpha}$ predominates over IL-1 in anti-GBM-induced nephritis, as assessed by the effects of blocking antibodies and by treatment with IL-1 ra. The inability of IL-1 to cause upregulation of endothelial leukocyte adhesion molecules in renal glomeruli after intraarterial infusion, in contrast to the effects of $\mathrm{TNF}_{\alpha}$ (this report), also differs from our experience in the lung vasculature in which human recombinant IL-1 is readily able in vivo to cause upregulation of ELAM-1 and VCAM-1 in the vascular endothelium (27). With respect to the kidney, $\mathrm{TNF}_{\alpha}$ has been shown to induce morphological and contractile changes in mesangial cells (33) and can induce glomerular damage when infused into the rab- 
bit (34). The profound protection produced by anti-TNF $\mathrm{T}_{\alpha}$ in the rat model of nephritis suggests that $\mathrm{TNF}_{\alpha}$ may be the dominant cytokine in acute nephrotoxic nephritis. The discrepancy between the key role for ELAM-1 in IgG immune complex-induced alveolitis ( 3 ) and our inability to demonstrate its role in anti-GBM-induced nephritis, together with the differences in the roles of $\mathrm{TNF}_{\alpha}$ and IL-1 in immune complex-induced pulmonary vascular and glomerular damage, suggest that the endothelium in the two organs may respond in fundamentally different ways to mediators. Only the availability of primary early passage lines of vascular endothelial cells from these two organs will permit resolution of these problems.

Our use of the acute anti-GBM model of nephritis has been confined to the very early, neutrophil-dependent phases of nephritis in which immune complexes, while distributed diffusely along the GBM, have not yet become morphologically detectable as dense subepithelial and mesangial deposits. This is in contrast to the pattern of deposition of immune complexes in various forms of lupus nephritis and in serum sickness nephritis (35). In contrast to the early (heterologous) phase of nephrotoxic nephritis, the delayed (autologous) phase occurring 6-7 d after infusion of anti-GBM is associated with a mesangial monocytic cellular accumulation, which is distinctly different from the early phase of anti-GBM-induced nephritis in which no such change occurs. It would be of interest to determine if a similar pattern of cytokine engagement and adhesion molecule involvement occurs in the delayed (autologous) phase of glomerulonephritis.

The data in this report suggest that, although ICAM-1 (which is reactive with both LFA-1 and Mac-1 (CD11b/ CD18)) is required for the full development of glomerular injury in the acute nephritis model, Mac-1 but not LFA-1 engagement is requisite. To what extent this pattern will apply in other models of neutrophil-mediated injury in rats cannot be predicted. ICAM-1 has been shown to be upregulated in autoimmune murine lupus nephritis (36), but the nature of its role in this model has not been defined. In other inflammatory models, CD18 has been shown to be involved in neutrophil accumulation in rabbit skin and subcutaneous sites (injected with FMLP, C5a, $\mathrm{LTB}_{4}$, or live bacteria) and at sites containing IgG immune complexes deposits and in lungs instilled with phorbol ester or Escherichia coli $(5,6)$. CD1 lb also plays a role in the full development of injury after myocardial ischemia-reperfusion in dog hearts, in which neutrophils also apparently contribute to injury (7).

The striking immunohistochemical evidence for the presence of VCAM-1 in the glomerular vasculature after infusion of anti-GBM suggests that this adhesion molecule may be relevant to the pathways leading to injury. The lack of adequate amounts of blocking antibody to VCAM-1 has precluded direct experimental testing of this question. Since VLA-4 is expressed on monocytes and on activated $T$ cells (but not on neutrophils) and because anti-VLA-4 is protective against the full development of proteinuria in the anti-GBM model of nephritis, it is possible that recruitment of monocytes into the mesangium after deposition of anti-GBM is linked to the pathophysiology of the nephritis. Alternatively, it is also possible that the presence of anti-GBM and related mediator production (e.g., complement activation products) results in a VLA-4-dependent activation of mesangial macrophages, with resultant cytokine production.

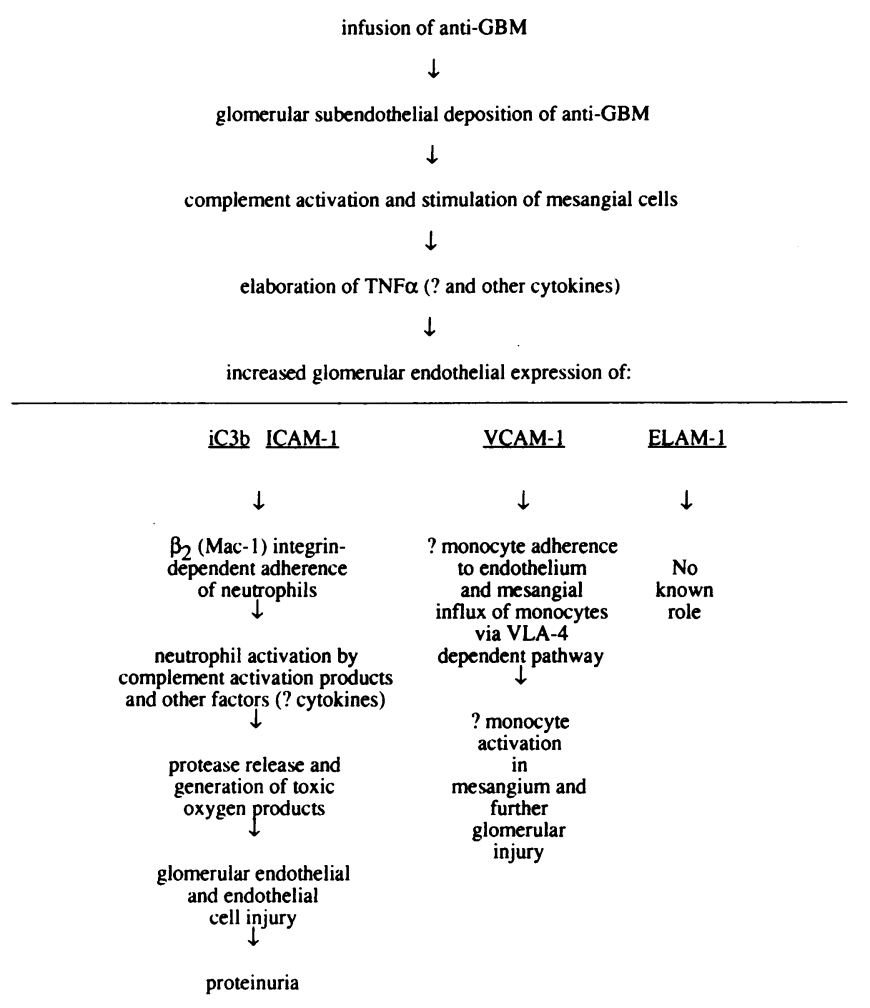

Figure 4. Proposed pathophysiological events in the early (acute, heterologous) phase of nephrotoxic nephritis.

The sequence of possible pathophysiological events in antiGBM-induced nephritis is depicted in Fig. 4. In this scheme, fixation of antibcidy to GBM and associated activation of complement leads to stimulation of mesangial cells which elaborate $\mathrm{TNF}_{\alpha}$ and perhaps other cytokines. In addition to its ability to "prime" mesangial cells, $\mathrm{TNF}_{\alpha}$ appears to play a major role in causing upregulation of glomerular endothelial leukocyte adhesion molecules such as VCAM-1, ELAM-1, and ICAM-1. The inability of CL-3 anti-ELAM-1, which is highly protective against IgG immune complex-induced lung injury (3), to reduce glomerular accumulation of neutrophils (Table II) or to protect the kidney against anti-GBM induced injury (Table I) suggests that upregulation of ELAM-1 may be adventitious. The upregulation of ICAM-1 provides a $\beta 2$ integrin-dependent pathway of adhesion of neutrophils to glomerular endothelial cells via Mac-1 (Mo1), coupled with the contemporaneous activation of neutrophils by complement activation products and (perhaps by $\mathrm{TNF}_{\alpha}$ ), resulting in damage/destruction of glomerular endothelial epithelial cells. It is also possible that Mac-1 engagement might occur in the context of the anti-GBM model via iC3b deposition related to the GBM-anti-GBM immune complexes. In this case, Mac-1 might be interactive with both ICAM-1 as well as iC 3 b, the latter being consistent with a very early complement-dependent adhesion-promoting process involving both neutrophils and endothelial cells (37). To what extent $\mathrm{Fc}$ receptor engagement may be involved in the intraglomerular localization of neutrophils in anti-GBM-injected animals is unclear. Whether monocyte recruitment into the mesangium occurs during the first $24 \mathrm{~h}$ after infusion of anti-GBM is uncertain. It is also not known if monocyte interaction with the endothelium in the early stages of this nephritis 
model might represent an important pathophysiological event and might be relevant to the blocking effects of anti-VLA-4. It is also possible that, if monocyte involvement in the model of glomerular injury is important, monocytes could also be the source of $\mathrm{TNF}_{\alpha}$. Activation of glomerular mesangial cells and production of $\mathrm{TNF}_{\alpha}$ after infusion of anti-GBM seems relevant to the processes leading to acute glomerular injury. It is also possible that an outcome of a VCAM-1 and VLA-4 driven event may be the accumulation of monocytes (and perhaps $T$ cells) in the glomerular mesangium, setting the stage for the delayed phase of nephritis. Finally, the requirement for Mac-1 but not LFA-1 for anti-GBM-induced glomerular injury may also be related to recent observations indicating that formyl chemotactic peptide-stimulated neutrophils in contact with endothelial monolayers produce significant amounts of $\mathrm{H}_{2} \mathrm{O}_{2}$ in a manner that is CD1 $1 \mathrm{~b}$ and CD18 dependent but independent of a role for $\operatorname{CD} 11 \mathrm{a}(16,38)$. This might be a relevant mechanism, since it has also been shown that in the anti-GBM model of nephritis infusion of catalase is highly protective (8) as is complement and neutrophil depletion (24).

Collectively, these data suggest that, in anti-GBM-induced nephritis, which is known to be complement dependent and related to generation of toxic oxygen products from neutrophils, TNF $\alpha$, VLA-4, ICAM-1, and Mac-1 are required (but not ELAM-1, LFA-1, or IL-1) for the full expression of glomerular injury. This pattern of mediator engagement is in striking contrast to IgG immune complex-induced lung injury which requires ELAM-1 (as well as $\mathrm{TNF}_{\alpha}, \mathrm{IL}-1$, and CD18) for full development of injury $(3,16-19)$. Either different mediators are produced in the two organs in response to deposits of immune complexes, or the vasculatures of the two organs respond in fundamentally different ways to inflammatory stimuli.

\section{Acknowledgments}

We acknowledge the contribution of Mary Anne Tishma in the preparation of this manuscript, the help of Ms. Robin G. Kunkel in preparation of the electron micrographs, and the generosity of Dr. James Rusche, Repligen Corp. (Cambridge, MA) for anti-rat CD11b, Drs. Robert Thompson and Tadahiko Kohno, Synergen Co. (Denver, CO) for IL-1 ra and sTNFr-1, and Dr. Roy Lobb, Biogen Co. (Cambridge, MA) for antibody to VCAM-1.

Supported in part by National Institutes of Health grants HL31963, GM-29507, GM-28737, GM-39397, CA-39064, HL-40526, HL-42550, AI-23521, and AI-19031, and by American Cancer Society grant IM-432.

\section{References}

1. Polley, M. J., M. L. Phillips, E. Wayner, E. Nudelman, A. K. Singhal, S.-I. Hakomori, and J. C. Paulson. 1991. CD62 and endothelial cell-leukocyte adhesion molecule 1 (ELAM-1) recognize the same carbohydrate ligand, sialyl Lewis ${ }^{x}$. Proc. Natl. Acad. Sci. USA. 88:6224-6228.

2. Smith, C. W., T. K. Kishimoto, O. Abbassi, B. Hughes, R. Rothein, L. V. McIntre, E. Butcher, and D. C. Anderson. 1990. Chemotactic proteins reduce lectin adhesion molecule-1 (LECAM-1)-dependent neutrophil adhesion to cytokine-stimulated endothelial cells in vitro. J. Clin. Invest. 87:609-618.

3. Mulligan, M. S., J. Varani, M. K. Dame, C. L. Lane, C. W. Smith, D. C. Anderson, and P. A. Ward. 1991. Role of ELAM-1 in neutrophil-mediated lung injury in rats. J. Clin. Invest. 88:1396-1406.

4. Freyer, D. R., M. L. Morganroth, and R. F. Todd III. 1989. Surface Mol (CD1 lb, CD18) glycoprotein is up-regulated in neutrophils recruited to sites of inflammation in vivo. Inflammation. 13:495-505.

5. Nourshargh, S., M. Rampart, P. G. Hellewell, P. J. Jose, J. M. Harlan, A. J.
Edwards, and T. J. Williams. 1989. Accumulation of ${ }^{111}$ In-neutrophils in rabbit skin in allergic and non-allergic inflammatory reactions in vivo. Inhibition by neutrophil pretreatment in vitro with a monoclonal antibody recognizing the CD18 antigen. J. Immunol. 142:3193-3198.

6. Doerschuk, C. M., R. K. Winn, H. O. Coxson, and J. M. Harlan. 1990. CD18-dependent and independent mechanisms of neutrophil emigration in the pulmonary and systemic microcirculation of rabbits. J. Immunol. 144:23272333.

7. Simpson, P. J., R. F. Todd III, J. C. Fantone, J. C. Mickelson, J. D. Griffin, and B. R. Lucchesi. 1988. Reduction of experimental canine myocardial reperfusion injury by a monoclonal antibody (anti-Mol, anti-CD11b) that inhibits leukocyte adhesion. J. Clin. Invest. 81:624-629.

8. Rehan, A., K. J. Johnson, R. C. Wiggins, R. G. Kunkel, and P. A. Ward. 1984. Evidence for the role of oxygen radicals in acute nephrotoxic nephritis. Lab. Invest. 51:396-403.

9. Cotran, R. S., M. J. Gimbrone III, M. P. Bevilaqua, D. L. Mendrick, and J. S. Pober. 1986. Induction and detection of a human endothelial activation antigen in vivo. J. Exp. Med. 164:661-666.

10. Bevilaqua, M. D., J. S. Pober, D. L. Mendrick, R. S. Cotran, and M. A. Gimbrone, Jr. 1987. Identification of an inducible endothelial leukocyte adhesion molecule. Proc. Natl. Acad. Sci. USA. 84:6238-6242.

11. Carlos, T. M., and J. M. Harlan. 1990. Membrane proteins involved in phagocyte adherence to endothelium. Immunol. Rev. 114:5-28.

12. Tamatani, T., and M. Miyasaka. 1990. Identification of monoclonal antibodies reactive with the rat homologue of ICAM-1 and evidence for differential involvement of ICAM- 1 in the adherence of resting versus activated lymphocytes to high endothelial cells. Intern. Immunol. 2:166-171.

13. Issekutz, T. B., and A. Wykretowicz. 1991. Effect of a new monoclonal antibody, TA-2, that inhibits lymphocyte adherence to cytokine stimulated endothelium in the rat. J. Immunol. 147:109-116.

14. Issekutz, T. B. 1991. Inhibition of in vivo lymphocyte migration to inflammation and homing to lymphoid tissues by the TA-2 monoclonal antibody: a likely role for VLA-4 in vivo. J. Immunol. 147:4178-4184.

15. Tamatani, T., M. Kotani, and M. Miyasaka. 1991. Characterization of the rat leukocyte integrin, CD11/CD18, by the use of LFA-1 subunit-specific monoclonal antibodies. Eur. J. Immunol. 21:627-633.

16. Mulligan, M. S., J. Varani, J. S. Warren, G. O. Till, C. W. Smith, D. C. Anderson, R. F. Todd III, and P. A. Ward. 1992. Roles of $\beta 2$ integrins of rat neutrophils in complement- and oxygen radical-mediated acute inflammatory injury. J. Immunol. 148:1847-1857.

17. Warren, J. S., K. B. Yabroff, D. G. Remick, S. L. Kunkel, S. W. Chensue, R. G. Kunkel, K. J. Johnson, and P. A. Ward. 1989. Tumor necrosis factor participates in the pathogenesis of acute immune complex alveolitis in the rat. $J$. Clin. Invest. 84:1873-1882.

18. Chensue, S. W., D. G. Remick, C. Shmyr-Forsch, T. F. Beals, and S. L. Kunkel. 1988. Immunohistochemical demonstration of cytoplasmic and membrane associated tumor necrosis factor in murine macrophages. Am. J. Pathol. 133:564-572.

19. Warren, J. S. 1991. Intrapulmonary interleukin-1 mediates acute immune complex alveolitis in the rat. Biochem. Biophys. Res. Commun. 175:604-610.

20. Hale, K. J., C. G. Smith, R. W. Vanderskee, S. Baker, D. A. Russell, R. I. Rivera, D. Dripps, and H. Kohno. 1991. Demonstration of in vitro and in vivo efficiency of two biologically active human soluble TNF receptors expressed in $E$ coli. J. Cell. Biochem. Suppl. 113:15F.

21. Engelmann, H., D. Novick, and D. Wallach. 1990. Two tumor necrosis factor-binding proteins purified from human urine: evidence for immunological cross-reactivity with cell surface tumor necrosis factor receptors. J. Biol. Chem. 265:1531-1536.

22. Wakabayashi, G., J. A. Gelfand, J. F. Burke, R. C. Thompson, and C. A Dinarello. 1991. A specific receptor antagonist for interleukin 1 prevents Escherichia coli-induced shock in rabbits. FASEB (Fed. Am. Soc. Exp. Biol.) J. 5:338343.

23. Hannum, C. H., C. J. Wilcox, W. P. Arend, F. G. Joslin, D. J. Dripps, P. L. Heimdal, L. G. Armes, A. Sommer, S. P. Eisenberg and R. C. Thompson. 1990 Interleukin-1 receptor antagonist activity of a human interleukin-1 inhibitor. Nature (Lond.). 343:336-340.

24. Hammer, D. K., and F. J. Dixon. 1963. Experimental glomerulonephritis II. Immunologic events in the pathogenesis of nephrotoxic serum nephritis in the rat. J. Exp. Med. 117:1019-1034.

25. Barker, J. N. W., R. S. Mitra, C. E. M. Griffiths, V. M. Dixit, and B. J. Nickoloff. 1991. Keratinocytes as initiators of inflammation. Lancet. 337:211214.

26. Picker, L. J., T. K. Kishimoto, C. W. Smith, R. A. Warnock, and E. C. Butcher. 1991. ELAM-1 is an adhesion molecule for skin-homing T cells. Nature (Lond.). 349:796-799.

27. Mulligan, M. S., and P. A. Ward. 1992. Immune complex-induced lung and dermal vascular injury: differing requirements for $\mathrm{TNF}_{\alpha}$ and IL-1. J. Immunol. 149:331-339. 
28. Friedl, H. P., G. O. Till, U. S. Ryan, and P. A. Ward. 1989. Mediator-induced activation of xanthine oxidase in endothelial cells. FASEB (Fed. Am. Soc Exp. Biol.) J. 3:2512-2518.

29. Casmussi, G., C. Tetta, F. Bussolino, E. Turello, S. J. Brentjen, G. Montruehio, and G. Anonus. 1990. Effect of leukocyte stimulation on rabbit immune complex glomerulonephritis. Kidney Int. 38:1047-1055.

30. Brennan, D. L., M. Yui, R. Wuthrich, and V. Kelley. 1989. Tumor necrosis factor and IL-1 in New Zealand black/white mice: enhanced gene expression and acceleration of renal injury. J. Immunol. 143:3430-3475.

31. Tomosugi, N., S. Cashman, H. C. Pusey, D. Evan, A. Shaw, and A. Rees. 1989. Modulation of antibody-mediated glomerular injury in vivo by bacterial lipopolysaccharide, tumor necrosis factor and IL-1. J. Immunol. 142:3083-3090.

32. Cook, T., J. Smith, and J. Cattell. 1991. Macrophage infiltration and interleukin-1 production accelerated nephrotoxic nephritis: effect of PGE1. Kidney Int. 37:411. (Abstr.)

33. Casmussi, G., E. Turrello, C. Tetta, F. Bussolino, and G. Baglioni. 1990.
Tumor necrosis factor induces contraction of mesangial cells and alters their cytoskeletons. Kidney Int. 38:795-802.

34. Bertani, T., M. Abbati, C. Zoja, N. Pericon, P. Ghezzi, and G. Remuzzi. 1989. Tumor necrosis factor induces glomerular damage in the rabbit. Am. J. Pathol. 134:419-430.

35. Couser, W. G. 1988. Rapidly progressive glomerulonephritis: classification, pathogenic mechanisms and therapy. Int. J. Kid. Dis. 11:449-464.

36. Wuthrich, R. P., A. M. Jevnikar, F. Takai, L. H. Glimcher, and V. E. Kelley. 1990. Intercellular adhesion molecule-1 (ICAM-1) expression is upregulated in autoimmune murine lupus nephritis. Am. J. Pathol. 136:441-450.

37. Marks, R. M., R. F. Todd III, and P. A. Ward. 1989. Rapid induction of neutrophil-endothelial adhesion by endothelial complement fixation. Nature (Lond.). 339:314-317.

38. Shappell, S. B., C. Toman, D. C. Anderson, A. A. Taylor, M. L. Entman, and C. W. Smith. 1990. Mac-1 (CD1 lb/CD18) mediates adherence-dependent hydrogen peroxide production by human and canine neutrophils. J. Immunol. 144:2702-2711. 